\title{
Drug Development Pipeline for Myeloproliferative Neoplasms: Potential Future Impact on Guidelines and Management
}

\author{
Prithviraj Bose, MD, and Srdan Verstovsek, MD, PhD
}

\begin{abstract}
The unprecedented success of ruxolitinib in myelofibrosis (MF) has paved the way for the development of other Janus kinase (JAK) inhibitors and other agents representing diverse drug classes and mechanisms of action in myeloproliferative neoplasms (MPNs). In particular, the symptomatic benefits afforded by ruxolitinib have led to the recognition of "clinical improvement" in symptoms and the spleen in international consensus response criteria for MF. Ruxolitinib is also approved for the second-line treatment of polycythemia vera and is being developed for essential thrombocythemia. Appreciation of the universal role of activated JAK/signal transducer and activator of transcription (STAT) signaling in MPNs and improved understanding of the canonical and noncanonical actions of JAK2 have yielded a number of drug targets beyond JAK2 in MPNs, which form the basis for a number of ruxolitinib-based rational combinations that are being explored in MF. Other JAK inhibitors with the potential for significantly less myelosuppression or even improvement of anemia continue to be tested. Finally, agents with very distinct mechanisms of action, such as novel interferon formulations, antifibrotic agents, and telomerase inhibitors, are being pursued in polycythemia vera and MF, respectively. This article reviews the current landscape of clinical drug development in MPNs, focusing on the most promising agents and combinations.
\end{abstract}

J Natl Compr Canc Netw 2016;14(12):1613-1624

\section{Background}

2016 marks the inception of formal management guidelines from NCCN on the Philadelphia chromosome-negative myeloproliferative neoplasms (MPNs). Guidelines recently released by $\mathrm{ESMO}^{1}$ distinguished between the major goals of therapy in essential thrombocythemia (ET) and polycythemia vera (PV) - the prevention of thrombosis and bleeding-from those in myelofibrosis $(\mathrm{MF})$, in which prolongation of survival and management of anemia, constitutional symptoms, and splenomegaly are most important. Underlying these disparate goals of therapy is the fundamentally different natural history of these MPNs: survival in MF is short (median, 6.5 years in 1996-2007 in one international study), ${ }^{2}$ whereas ET and PV are each characterized by an indolent clinical course and prolonged survival, al-

From The University of Texas MD Anderson Cancer Center, Houston, Texas. Submitted July 19, 2016; accepted for publication September 19, 2016. Dr. Bose has disclosed that he has received honorarium from Incyte Corporation. Dr. Verstovsek has disclosed that he has received research funding from Incyte Corporation, AstraZeneca, Lilly Oncology, Roche, though shorter than that of the age- and sex-matched US population.,

MPNs are characterized by universal activation of Janus kinase/signal transducer and activator of transcription (JAK-STAT) signaling, ${ }^{5,6}$ in most cases due to gain-of-function mutations in JAK2, ${ }^{7-11} \mathrm{MPL},{ }^{12,13}$ or CALR. ${ }^{14,15}$ The first-in-class JAK1/2 inhibitor, ruxolitinib, approved for the treatment of intermediate- or high-risk $\mathrm{MF}^{16,17}$ and hydroxyurea-resistant/intolerant PV (see Table 1 for definition of resistance and intolerance to hydroxyurea), ${ }^{18}$ represents the first example of disease-modifying pharmacologic therapy in MPNs, and the inaugural NCCN Clinical Practice Guidelines in Oncology (NCCN Guidelines) contain special guidance on the use of ruxolitinib (in this issue; to view the most recent version, visit NCCN.org). Long-term follow-up of the pivotal COMFORT trials has demon- 
Bose and Verstovsek

Table 1. Definition of Resistance/Intolerance to Hydroxyurea in Polycythemia Vera

1. Need for phlebotomy to keep hematocrit $<45 \%$ after 3 months of $\geq 2 \mathrm{~g} / \mathrm{d}$ of hydroxyurea, OR

2. Uncontrolled myeloproliferation (ie, platelets $>400 x$ $10 \%$ L AND leukocytes $>10 \times 10^{9} / \mathrm{L}$ after 3 months of $\geq 2$ $\mathrm{g} / \mathrm{d}$ of hydroxyurea), OR

3. Failure to reduce massive ${ }^{a}$ splenomegaly by $\geq 50 \%$ as measured by palpation, OR failure to completely relieve symptoms related to splenomegaly after 3 months of $\geq 2 \mathrm{~g} / \mathrm{d}$ of hydroxyurea, OR

4. Absolute neutrophil count $<1.0 \times 10 \% / \mathrm{L}$ OR platelet count $<100 \times 10^{9} / \mathrm{L}$ OR hemoglobin $<100 \mathrm{~g} / \mathrm{L}$ at the lowest dose of hydroxyurea required to achieve a complete or partial clinicohematologic response, ${ }^{\mathrm{b}}$ OR

5. Presence of leg ulcers or other unacceptable hydroxyurea-related nonhematologic toxicities, such as mucocutaneous manifestations, gastrointestinal symptoms, pneumonitis, or fever at any dose of hydroxyurea

aOrgan extending by $>10 \mathrm{~cm}$ from the costal margin

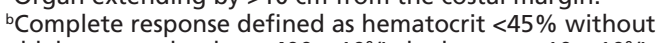
phlebotomy, platelets $\leq 400 \times 10^{9} / \mathrm{L}$, leukocytes $\leq 10 \times 10^{9} / \mathrm{L}$, and no disease-related symptoms. Partial response defined as hematocrit $<45 \%$ without phlebotomy or response in $\geq 3$ of the other criteria. ${ }^{105}$ Modified from Barosi G, Birgegard G, Finazzi G, et al. A unified definition of clinical resistance and intolerance to hydroxycarbamide in polycythaemia vera and primary myelofibrosis: results of a European LeukemiaNet (ELN) consensus process. Br J Haematol 2010;148:962.

strated that ruxolitinib improves overall survival in patients with intermediate-2- or high-risk MF when compared with placebo and best available therapy (BAT), respectively, despite extensive crossover, ${ }^{19,20}$ as well as reduces the mutated JAK2 allelic burden and improves bone marrow (BM) fibrosis in a minority of patients. ${ }^{20}$ The salutary benefits of this agent on constitutional symptoms of $\mathrm{MF}^{21}$ led to the recognition of clinical improvement in symptoms as a response criterion by the International Working Group-Myeloproliferative Neoplasms Research and Treatment (IWG-MRT), ${ }^{22}$ resulting in the incorporation of the MPN Symptom Assessment Form Total Symptom Score (MPN-SAF TSS) ${ }^{23}$ as a tool for formal assessment of symptom response in MPNs. Ruxolitinib is effective without regard for the mutational status of JAK2.16,17,24 These successes have led to a wave of clinical trials of ruxolitinib-based rational combinations with other novel targeted agents, as well as antianemia medications, in $\mathrm{MF}^{25}$ Simultaneously, development of other JAK inhibitors and new classes of agents with therapeutic promise in MF has continued. However, allogeneic hematopoietic stem cell transplantation (HSCT), recommended in pa- tients younger than 70 years with intermediate-2- or high-risk disease, as well as in those younger than 65 years with intermediate-1-risk disease but with known poor-risk features (eg, red cell transfusion dependence, $>2 \%$ circulating blasts, or adverse cytogenetics) remains the only potential cure for $\mathrm{MF}^{26} \mathrm{Al}$ though widely used, especially for spleen shrinkage, the optimal duration of JAK inhibitor therapy before HSCT remains unknown. There is also interest in the use of these drugs post-HSCT, particularly in light of recent findings supporting a role for JAK1/2 inhibitors in treating graft-versus-host disease. ${ }^{27,28}$

\section{Drug Development in PV and ET}

The indolent natural course of PV and ET, leading to prolonged overall survival, ${ }^{3,4}$ has meant that drug therapy in these conditions has mostly been limited to the use of aspirin ${ }^{29}$ and hydroxyurea or anagrelide (in ET) in high-risk patients requiring cytoreduction for prevention of thrombotic complications. ${ }^{30-32} \mathrm{He}$ matocrit control (to $<45 \%)^{33}$ in low-risk patients with PV is usually achieved with phlebotomy alone. However, patients with PV and ET, especially the former, can have a substantial symptom burden. ${ }^{23,34-36}$ In the RESPONSE trial, which led to the recent approval of ruxolitinib for the treatment of hydroxyurea-resistant/ intolerant PV, $49 \%$ of patients in the ruxolitinib group achieved a $50 \%$ or more reduction in their total symptom score (TSS) at 32 weeks compared with 5\% in the standard therapy group. ${ }^{18}$ Hematocrit control was achieved by $60 \%$ versus $20 \%$, respectively, and a $35 \%$ or more spleen volume reduction (SVR) by $38 \%$ and 1\%, respectively. ${ }^{18}$ Additionally, 24\% in the ruxolitinib arm achieved complete hematologic remission (CHR) compared with $9 \%$ in the standard therapy $\operatorname{arm}^{18}$; these benefits were maintained in most patients after a minimum of 80 weeks of follow-up. ${ }^{37}$ No patient lost their spleen response between weeks 32 and 80 , and $90 \%$ of patients still receiving ruxolitinib at week 32 had no phlebotomies performed during this period. RESPONSE was not designed to evaluate rates of thrombosis, but at week 32 , before crossover to ruxolitinib, there were 6 thromboembolic events in the standard therapy arm and only 1 in the ruxolitinib arm. ${ }^{18}$ At the 80 -week analysis, the rates of all-grade and grade 3/4 thromboembolic events per 100 patient-years of exposure were 1.8 and 0.9 , respectively, among patients originally randomized to ruxolitinib, 
Drug Development in Myeloproliferative Neoplasms

versus 4.1 and 2.7 in those receiving ruxolitinib after crossover, and 8.2 and 2.7 in those receiving BAT. ${ }^{37}$ Because ruxolitinib is immunosuppressive, infections are a concern with this agent. Grade $1 / 2$ herpes zoster infections occurred in 7 patients in the ruxolitinib group $(6.4 \%)$ compared with none in the standard therapy group through week $32 .{ }^{18}$ With longer follow-up (minimum 80 weeks), rates remained higher with ruxolitinib: 5.3 and 5.4 per 100 patient-years of exposure among patients originally randomized to and those who crossed over to ruxolitinib, respectively, versus none among patients receiving standard therapy. ${ }^{37}$ Overall, the rate of infections (any grade) was $41.8 \%$ in the ruxolitinib group and $36.9 \%$ in the standard-therapy group; the rate of grade $3 / 4$ infection was $3.6 \%$ and $2.7 \%$, respectively, in the primary analysis. ${ }^{18}$ Per 100 patient-years of exposure, the rates of all-grade and grade 3/4 infections were 29.4, 27.8, and 58.4 , and 4.0, 5.4, and 4.1 for patients originally randomized to ruxolitinib $(\mathrm{n}=110)$, those crossed over to ruxolitinib ( $\mathrm{n}=98)$, and those originally assigned to BAT $(n=111)$, respectively. ${ }^{37}$ Evaluation of ruxolitinib in patients with ET is ongoing (ClinicalTrials. gov identifiers: NCT00726232, NCT02577926).

Although not specifically approved for MPN therapy, high response rates, including molecular responses, have been reported with the use of pegylated interferon- $\alpha-2 \mathrm{a}$ in both PV and ET. ${ }^{38,39}$ One study in 40 patients with PV reported a CHR rate of $94.6 \%$ and a decrease in the percentage of mutated JAK2 in $89.6 \%$ of patients, with improvement over time in the depth of molecular responses. ${ }^{38} \mathrm{~A}$ total of 7 patients achieved a complete molecular remission (CMR), which persisted after treatment discontinuation in 5 patients. ${ }^{38}$ In another study, CHR rates of $70 \%$ and $76 \%$ were reported among patients with PV and ET, respectively, with molecular response rates of 38\% in ET and 54\% in PV (CMR in 6\% and 14\%, respectively). ${ }^{39}$ After a median follow-up of 82.5 months, 32 of 83 enrolled patients $(39 \%)$ remained on this study, but therapy was on hold for 8 of these patients. ${ }^{40}$ The median durations of hematologic and molecular responses were 66 and 53 months, respectively. ${ }^{40} \mathrm{JAK} 2$ status or allele burden had no impact on achievement of response (clinical or molecular), time to response, or duration of therapy, but patients achieving CMR had the longest response duration. ${ }^{40}$ Pegylated interferon- $\alpha-2 \mathrm{a}$ also significantly decreased the allelic burden of mutant CALR from a median of $41 \%$ at baseline to $26 \%$ after treatment in a study of 31 patients with CALR-mutated ET, with 2 patients achieving CMR. ${ }^{41}$

Recently, a next-generation, mono-PEGylated interferon- $\alpha-2 b$ isoform with a long elimination halflife enabling administration every 2 weeks, ropeginterferon $\alpha-2 b$, has been developed for PV. ${ }^{42}$ In a phase I/II trial in 51 patients, there were no dose-limiting toxicities and the overall response rate was $90 \%$, including CHR in $47 \% .^{42} \mathrm{~A} \mathrm{CMR}$ was obtained in $21 \%$ of patients and a partial molecular response in $47 \% .^{42}$ A steady decrease in the allelic burden of JAK2 V617F was also noted with ruxolitinib therapy in the RESPONSE trial in patients with hydroxyurea-resistant/intolerant PV; the mean percentage decrease from baseline was $40 \%$ by week 208 (12.2\% at week $32 ; 22 \%$ at week 80$) .37,43$ Although decreases in JAK2 V617F allelic burden are often considered to represent evidence of disease-modifying activity, it is important to remember that although it is the most common mutation in MPN, JAK2 V617F is not the disease-initiating mutation ${ }^{44}$ and can be a late genetic event. ${ }^{45}$ For example, TET2 mutations can precede JAK2 mutations, and the order of mutation acquisition can affect disease phenotype, thrombosis risk, and in vitro sensitivity of JAK2-mutant progenitors to ruxolitinib, as well as the proliferative response to JAK2 V617F.46 Importantly, notwithstanding its effects on JAK2 V617F-positive clones, pegylated interferon$\alpha$-2a appears not to affect TET2-mutant cells. ${ }^{47}$ In the study of CALR-mutated ET mentioned earlier, molecular responses to pegylated interferon- $\alpha$ were poorer (minor to no molecular responses) in patients who also had TET2, ASXL1, IDH2, and/or TP53 mutations. ${ }^{41}$ All patients who achieved a CMR or partial molecular response to pegylated interferon- $\alpha$ had no additional mutations besides CALR. ${ }^{41}$ Achievement of a complete molecular response (in terms of JAK2 V617F but not TET2) to ruxolitinib, though infrequent, has been reported in patients with PV and ET ( 3 of 22 patients in one study at the 5 -year time point)..$^{48}$

The telomerase inhibitor, imetelstat, was evaluated in a small phase II study in 18 patients with previously treated ET, with a primary end point of best hematologic response. ${ }^{49}$ All patients responded at some point in time, and $16(89 \%)$ had a CHR as their best response. Molecular responses occurred in 7 of 8 patients with JAK2 V617F-positive mutations; CALR and MPL mutant allele burdens also decreased by $15 \%$ to $66 \%$. Myelosuppression and hepatotoxicity were the major adverse events. ${ }^{49}$ Imetelstat is 
administered intravenously, and was initially administered once weekly in this study (maintenance dosing at a reduced frequency began after achievement of a CHR or partial hematologic response), a route and schedule that may be hard to justify when treating an indolent disease with a long natural history (median survival, 19.8 years even at a large, tertiary care referral center). ${ }^{3}$ Histone deacetylase inhibitors (HDACIs) are efficacious preclinically in MPN, both in vitro and in vivo, ${ }^{50,51}$ and are clearly active in patients with PV and ET, but the chronic low-grade toxicities of these agents (eg, fatigue, diarrhea, nausea, myelosuppression) make them difficult to tolerate long-term. ${ }^{52-54}$

\section{Drug Development Pipeline in MF}

The need for disease-modifying therapies is significantly greater in MF than in PV or ET, owing to the substantially more aggressive disease biology in MF. Although current pharmacologic therapy of primary MF centers on ruxolitinib, ${ }^{55}$ efforts are ongoing to develop novel ruxolitinib-based combinations, new JAK2 inhibitors, and other classes of drugs, such as antifibrotic agents and telomerase inhibitors. Given the survival benefit of ruxolitinib in patients with advanced MF, ${ }^{16,19,56}$ it is now being studied in patients with earlier stages of MF and one or more prognostically detrimental mutations (ASXL1, EZH2, SRSF2, IDH1, IDH2) 57 in the ReTHINK trial (ClinicalTrials.gov identifier: NCT02598297).

\section{Ruxolitinib-Based Combination Strategies}

Combinations With Antianemia Medications: Anemia is both a hallmark of MF and an on-target effect of ruxolitinib, because erythropoiesis is critically dependent on JAK-STAT signaling. ${ }^{58}$ In fact, doselimiting anemia and thrombocytopenia have been suggested as one potential explanation for the rather modest effect of ruxolitinib on JAK2 V617F allele burden reduction in $\mathrm{MF}^{59}$ Medications generally used to alleviate the anemia of MF include danazol, erythropoiesis-stimulating agents (ESAs), immunomodulatory drugs (IMiDs; eg, thalidomide, lenalidomide, pomalidomide), and steroids. ${ }^{55}$ Anemia response rates to $\mathrm{IMiDs}$ are in the $20 \%$ to $30 \%$ range, whereas response rates to ESAs and androgens vary from $20 \%$ to $60 \% .{ }^{55}$ Naturally, there is considerable interest in combining these agents with ruxolitinib, monotherapy with which causes an initial decline in the hemoglobin level, followed by the establishment of a new lower baseline. ${ }^{16,17}$ However, the simultaneous administration of ruxolitinib and lenalidomide is difficult because of excessive myelosuppression. ${ }^{60}$

POMINC is a trial of ruxolitinib and pomalidomide in MF that is ongoing in Germany (ClinicalTrials.gov identifier: NCT01644110), and one of ruxolitinib and thalidomide is planned in the United States. Although in theory, JAK2 inhibition would be expected to antagonize the effects of ESAs ${ }^{58}$ in practice some improvement of anemia may be seen with the addition of ESAs to ruxolitinib. A trial of ruxolitinib plus danazol $(\mathrm{n}=14)$ was halted secondary to lack of anemia response ${ }^{61} ; 3$ patients $(21.4 \%)$ had clinical improvement in spleen size according to IWG-MRT criteria. ${ }^{22}$ These trials are listed in Table 2.

Finally, a new class of agents termed activin receptor IIA ligand traps have been shown to correct ineffective erythropoiesis and improve anemia in mouse models of $\alpha$-thalassemia through inactivation of GDF11, a cytokine that blocks terminal erythroid maturation. ${ }^{62}$ These drugs have shown considerable efficacy in myelodysplastic syndrome (MDS) with ringed sideroblasts, ${ }^{63}$ and evaluation in MF is ongoing, with plans for combination with ruxolitinib (ClinicalTrials.gov identifier: NCT01712308).

\section{Mechanism-Based Combinations With Other Tar-} geted Agents: A number of different classes of targeted agents continue to be explored in combination with ruxolitinib in MF. ${ }^{25}$ These include epigenetic therapies such as DNA methyltransferase inhibitors (DNMTI) and HDACIs, phosphatidylinositol-3-kinase $(\mathrm{PI} 3 \mathrm{~K}) / \mathrm{Akt} / \mathrm{mTOR}$ inhibitors, and hedgehog inhibitors. Table 2 lists ongoing trials of ruxolitinibbased combinations in MF.

Epigenetic abnormalities are frequent in MF, and JAK2 influences nuclear gene transcription in a variety of ways, such that a number of mechanisms ${ }^{64}$ underlie the synergism observed between JAK2 inhibitors and epigenetic modifiers in MF. For HDACIs, an important concept is the downregulation, through acetylation, by HDAC6 inhibitors of the chaperone protein, heat shock protein 90 , of which JAK2 is a client. ${ }^{65}$ This is a major mechanism through which HDACIs promote the degradation of JAK2 V617F and potentiate the effects of JAK2 inhibitors in MPN cells. ${ }^{66} \mathrm{HDACI}$ monotherapy is definitely active in MF in terms of symptom and spleen responses 
Drug Development in Myeloproliferative Neoplasms

Table 2. Clinical Trials (Nontransplant) of Ruxolitinib-Based Combinations in MF

\section{Clinicaltrials.} gov Identifier

Partner Drug

INCB050465 (PI3K

Major Inclusion Criteria

Phase

Comments

\begin{tabular}{ll}
\hline NCT02718300 & $\begin{array}{l}\text { INCB050465 (PI3K } \\
\text { delta inhibitor) }\end{array}$
\end{tabular}

$\begin{array}{ll}\text { NCT01433445 } & \begin{array}{l}\text { Panobinostat } \\ \text { (HDAC inhibito }\end{array}\end{array}$

PMF or post-PV/ET MF; spleen $>10$ $\mathrm{cm}$ below LCM or 5-10 $\mathrm{cm}$ with MF symptoms

\begin{tabular}{|ll|} 
& (HDAC inhibitor) \\
\hline NCT01693601 & $\begin{array}{l}\text { Panobinostat } \\
\text { (HDAC inhibitor) }\end{array}$ \\
\hline NCT01732445 & Danazol \\
\hline NCT02370706 & $\begin{array}{l}\text { PIM447 (PIM kinase } \\
\text { inhibitor) and/or } \\
\text { LEE011 (CDK4/6 } \\
\text { inhibitor) }\end{array}$ \\
\hline
\end{tabular}

PMF or post-PV/ET MF; spleen $\geq 5 \mathrm{~cm}$

I/II below LCM, platelets $>100 \times 10^{9} / \mathrm{L}$,

II $<10 \%$ blasts

PMF or post-PV/ET MF in CP or AP; intermediate-2- or high-risk; platelets $\geq 75 \times 10^{\circ} / \mathrm{L}$, ANC $\geq 0.75 \times 10^{\%} / \mathrm{L}$

PMF or post-PV/ET MF, intermediate- or high-risk; $\mathrm{Hgb}<10 \mathrm{~g} / \mathrm{dL}$ or TD; platelets $\geq 50 \times 10^{9} / \mathrm{L}$, ANC $\geq 1 \times 10^{9} / \mathrm{L}$
PMF or post-PV/ET MF, JAK2 V617Fpositive; splenomegaly $\geq 5 \mathrm{~cm}$ by $\mathrm{MRI}$; platelets $\geq 100 \times 10^{9} / \mathrm{L}, \mathrm{ANC} \geq 1.5 \times 10^{9} / \mathrm{L}$; $\mathrm{Hgb} \geq 9 \mathrm{~g} / \mathrm{dL}$ \begin{tabular}{|ll} 
NCT01787487 & Azacitidine (HM $)$ \\
NCT02493530 & $\begin{array}{l}\text { TGR-1202 (PI3K } \\
\text { delta inhibitor) }\end{array}$
\end{tabular}

PIM

\section{PMF or post-PV/ET MF, intermediate- or I high-risk if newly diagnosed; platelets $\geq 50 \times 10^{9} / \mathrm{L}, \mathrm{ANC} \geq 1 \times 10^{\circ} / \mathrm{L}$ PMF or post-PV/ET MF, intermediate- । or high-risk, with grade $\geq 1$ marrow fibrosis; patients with PV meeting rux indications}

\begin{tabular}{|ll|}
\hline NCT02436135 & $\begin{array}{l}\text { Idelalisib (PI3K } \\
\text { delta inhibitor) }\end{array}$ \\
\hline NCT02267278 & $\begin{array}{l}\text { Pracinostat (HDAC } \\
\text { inhibitor) }\end{array}$ \\
\hline
\end{tabular}

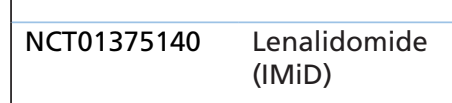

NCT01644110 Pomalidomide (IMiD)

PMF or post-PV/ET MF, intermediate- I or high-risk, with disease relapse or progression on rux

\section{PMF or post-PV/ET MF, intermediate- or II} high-risk if newly diagnosed, spleen $\geq 5$ $\mathrm{cm}$ below LCM ; platelets $\geq 50 \times 10^{\%} / \mathrm{L}$, ANC $\geq 1 \times 10^{\circ} / \mathrm{L}$

\section{PMF or post-PV/ET MF, intermediate- or II} high-risk if newly diagnosed; platelets $\geq 100 \times 10^{9} / \mathrm{L}$, ANC $\geq 1 \times 10^{9} / \mathrm{L}$ PMF or post-PV/ET MF, splenomegaly $>11 \mathrm{~cm}$ (total diameter) and/or leukoerythroblastosis; $\mathrm{Hgb}<10 \mathrm{~g} / \mathrm{dL}$ or TD; platelets $\geq 100 \times 10^{9} / \mathrm{L}$, ANC $\geq 0.5 \times 10^{9} / \mathrm{L}$

I/II

\section{II (pilot) Closed early ${ }^{61}$}

1
Dose escalation and expansion parts have different inclusion criteria: only patients with insufficient spleen response to $\geq 6$ mo of rux allowed in escalation phase II Completed accrual to MF arm ${ }^{74}$; currently accruing patients with MDS/MPN

Escalation stage 1 enrolls only patients with insufficient response to $\geq 8$ wk of rux; stage 2 is for JAK inhibitor-naïve patients; PI3K or mTOR inhibitors not allowed in prior 6 mo

Patients must have been on a stable dose of rux for $\geq 4 \mathrm{wk}$

Prior rux allowed only if duration <3 mo; no prior HDAC inhibitor allowed

Simultaneous administration of rux and lenalidomide is difficult due to excessive myelosuppression ${ }^{60}$ Although promising in a phase II study as a treatment for anemia of $\mathrm{MF}^{106}$ pomalidomide was not superior to placebo in a phase III study in $\mathrm{MF}^{107}$

\begin{tabular}{|lll} 
NCT02593760 & $\begin{array}{l}\text { Vismodegib } \\
\text { (Hedgehog } \\
\text { inhibitor) }\end{array}$ & $\begin{array}{l}\text { PMF or post-PV/ET MF, intermediate- or } \\
\text { high-risk; spleen }>5 \mathrm{~cm} \text { below } \mathrm{LCM} ; \\
\text { ANC }>1 \times 10^{9} / \mathrm{L}, \text { platelets } \geq 100 \times 10^{9} / \mathrm{L}, \\
<10 \% \text { peripheral blasts }\end{array}$ \\
\hline NCT02742324 & $\begin{array}{l}\text { Pegylated } \\
\text { interferon- } \alpha-2 a\end{array}$ & $\begin{array}{l}\text { PMF or post-PV/ET MF, intermediate- or } \\
\text { high-risk, with need for active therapy; } \\
\text { ANC } \geq 1.5 \times 10^{9} / \mathrm{L}, \text { platelets } \geq 150 \times 10^{9} / \mathrm{L}, \\
\end{array}$ \\
& $\leq 10 \%$ peripheral blasts
\end{tabular}

\begin{tabular}{|llll} 
NCT01787552 & $\begin{array}{l}\text { Sonidegib } \\
\text { (Hedgehog } \\
\text { inhibitor) }\end{array}$ & $\begin{array}{l}\text { PMF or post-PV/ET MF, symptomatic, } \\
\text { spleen } \geq 5 \mathrm{~cm} \text { below LCM, intermediate- } \\
\text { or high-risk; platelets } \geq 75 \times 10^{9} / \mathrm{L}\end{array}$ & I/II \\
\hline NCT02076191 & Decitabine (HMA) & MPN in AP or post-MPN AML & I/I/I \\
\hline NCT02257138 & Decitabine (HMA) & $\begin{array}{l}\text { Phase I portion: R/R AML } \\
\text { Phase II portion: post-MPN AML or } \\
\text { MDS/MPN with }>20 \% \text { blasts }\end{array}$ \\
\hline
\end{tabular}

Abbreviations: AML, acute myeloid leukemia; ANC, absolute neutrophil count; $\mathrm{AP}$, accelerated phase; $C D K$, cyclin-dependent kinase; $C P$, chronic phase; ET, essential thrombocythemia; HDAC, histone deacetylase; Hgb, hemoglobin; HMA, hypomethylating agent; IMiD, immunomodulatory drug; JAK, Janus kinase; LCM, left costal margin; MDS, myelodysplastic syndrome; MF, myelofibrosis; MPN, myeloproliferative neoplasm; PI3K, phosphatidylinositol-3-kinase; PMF, primary myelofibrosis; PV, polycythemia vera; RP2D, recommended phase II dose; R/R, relapsed/refractory; rux, ruxolitinib; TD, transfusion-dependent. 
and even improvement of anemia, but long-term therapy is required for disease-modifying effects (eg, regression of BM fibrosis) to emerge, and the tolerability of chronic therapy with these agents is an important concern. ${ }^{67-69}$ In a phase Ib trial ${ }^{70}$ of ruxolitinib and the pan-HDACI panobinostat in patients with intermediate- or high-risk ${ }^{71} \mathrm{MF}$ and palpable splenomegaly of $5 \mathrm{~cm}$ or greater, $15 \mathrm{mg}$ twice daily of ruxolitinib and $25 \mathrm{mg} 3$ times a week of panobinostat was found to be reasonably well-tolerated, and reductions in spleen volume and the allelic burden of mutant JAK2 by $35 \%$ or greater and $20 \%$ or greater, respectively, were achieved in a greater proportion of patients at earlier time points than has been reported with ruxolitinib alone. ${ }^{56}$

Although aberrant promoter hypermethylation is characteristic of PV and ET, primary MF is characterized by both aberrant hypermethylation and hypomethylation. ${ }^{72}$ The DNMTI azacitidine has limited clinical activity on its own in patients with $\mathrm{MF}^{73}$ but has been combined with ruxolitinib in a phase II trial in these patients. ${ }^{74}$ Azacitidine was introduced at a dose of $25 \mathrm{mg} / \mathrm{m}^{2} / \mathrm{d}$ for 5 days in 28 -day cycles after 3 months of ruxolitinib alone, with provision for gradual dose increase to $75 \mathrm{mg} / \mathrm{m}^{2} / \mathrm{d}$ as tolerated. The response rate ${ }^{22}$ among 28 evaluable patients was $82 \%$, with a median time to response of 1 month; 11 of 13 serially evaluable responders experienced a reduction in their JAK2 V617F allelic burden (2 experienced $>50 \%$ reduction) and 6 of $22(27 \%)$ had improvement in BM fibrosis grade. Most patients required dose interruptions and/or adjustments. ${ }^{74}$ In a study of 54 patients with post-MPN MDS or acute myeloid leukemia, azacitidine produced an overall response rate of $52 \%$ with a median response duration of 9 months and median overall survival of 11 months. ${ }^{75}$ Decitabine also appears active in patients with high-risk primary MF and MPN in accelerated or blastic phase, ${ }^{76}$ and clinical trials of ruxolitinib in combination with decitabine in the latter populations are ongoing (ClinicalTrials.gov identifiers: NCT02076191, NCT02257138).

Activation of the PI3K/Akt/mTOR pathway is an important downstream consequence of JAK-STAT signaling in $\mathrm{MPN},{ }^{77}$ and the dual PI3K/mTOR inhibitor, BEZ235, synergistically enhances the activity of JAK2 inhibitors against cultured and primary CD34positive MPN cells, with relative sparing of normal CD34-positive hematopoietic progenitor cells. ${ }^{78}$ Rux- olitinib was combined with the pan-PI3K inhibitor buparlisib in a 2-arm, phase Ib study in intermediateor high-risk patients with MF who could either be JAK inhibitor-naïve ( $\operatorname{arm} A, n=22$ ) or previously treated with JAK inhibitors ( $\operatorname{arm} \mathrm{B}, \mathrm{n}=20) .{ }^{79}$ The maximum tolerated dose for the combination was determined to be $15 \mathrm{mg}$ twice daily of ruxolitinib, along with 60 mg daily of buparlisib. A total of $55 \%$ and $20 \%$ of patients in arms A and B, respectively, achieved a 50\% or greater reduction in palpable spleen length (considered approximately equivalent to $\geq 35 \%$ SVR) at week 24 , but these percentages decreased to $45 \%$ and $18 \%$, respectively, when only patients in the expansion phase receiving uniform drug doses were considered. After 24 weeks of treatment at the maximum tolerated dose, only 4 patients (3 in arm A; 1 in arm B) exhibited an improvement in BM fibrosis, whereas 2 in arm A had worsening BM fibrosis. ${ }^{79}$ Although the IWG-MRT response rate ${ }^{22}$ to everolimus (mTOR inhibitor) monotherapy in intermediate- or high-risk MF was only $23 \%$, most patients experienced complete resolution of systemic symptoms. ${ }^{80}$

Excess hedgehog ligand secretion and loss of PTCH2, which drives canonical and noncanonical hedgehog signaling, have been described in MPN. ${ }^{81}$ The smoothened inhibitor, sonidegib, has been shown to improve leukocytosis and thrombocytosis, reduce the allelic burden of mutant JAK2, and significantly reduce $\mathrm{BM}$ fibrosis in a murine model of ET/MF. ${ }^{82}$ In a phase Ib/II study, the recommended phase II doses for combination ruxolitinib and sonidegib were found to be $20 \mathrm{mg}$ twice daily and $400 \mathrm{mg}$ daily, respectively. ${ }^{83}$ A total of 27 JAK inhibitor-naïve patients with intermediate- or high-risk MF and palpable splenomegaly were treated at these doses for a median of 28.6 weeks. Seventeen patients (63\%) experienced adverse events requiring dose adjustment or interruption. At the end of week 24,12 patients $(44.4 \%)$ had a $35 \%$ or greater reduction in spleen volume (although 15 [55.6\%] achieved $\geq 50 \%$ reduction in palpable spleen length), the mean reduction in JAK2 V617F allelic burden was $9 \%$, and 2 patients had an improvement in BM fibrosis, whereas 3 had worsening. ${ }^{83}$

\section{Newer JAK2 Inhibitors}

A number of investigational JAK2 inhibitors have been discontinued, mostly owing to toxicity concerns, and ruxolitinib remains the only one currently approved for oncologic indications. ${ }^{84}$ Among the 
other compounds, only momelotinib, pacritinib, and NS-018 remain in clinical trials. ${ }^{84}$ Table 3 lists ongoing trials of these agents in MF.

Momelotinib is a JAK1/2 inhibitor that may produce significant anemia responses, in addition to spleen and symptom responses, among patients with MF. ${ }^{85}$ Some data suggest that momelotinib inhibits ALK2-mediated expression of hepcidin in the liver, which results in increased release of iron from sequestered cellular stores and enhanced erythropoiesis. ${ }^{86} \mathrm{In}$ separate phase I/II studies $\left(n=166^{87}\right.$ and $n=61,{ }^{88}$ respectively) in patients with intermediate-2- or highrisk $^{71} \mathrm{MF}$, or intermediate-1-risk ${ }^{71} \mathrm{MF}$ with symptomatic organomegaly or unresponsiveness to available therapy, momelotinib produced spleen responses (by physical examination) in 39\% and 72\%, and anemia

\section{Table 3. Ongoing Clinical Trials (Nontransplant) of JAK Inhibitors Other Than Ruxolitinib in MF}

\begin{tabular}{|c|c|c|c|c|}
\hline $\begin{array}{l}\text { Clinicaltrials. } \\
\text { gov Identifier }\end{array}$ & Drug & Phase & Major Inclusion Criteria & Comments \\
\hline NCT02515630 & Momelotinib & II & $\begin{array}{l}\text { PMF or post-PV/ET MF requiring } \\
\text { therapy, intermediate-2- or high- } \\
\text { risk, or intermediate-1-risk with } \\
\text { symptomatic organomegaly, TD, } \\
\text { platelets } \geq 50 \times 10^{9} / \mathrm{L}\end{array}$ & $\begin{array}{l}\text { 21-day washout from prior JAK } \\
\text { inhibitor; grade } \geq 2 \text { PN not allowed }\end{array}$ \\
\hline NCT02101268 & Momelotinib & III & $\begin{array}{l}\text { PMF or post-PV/ET MF, spleen pal- } \\
\text { pable } \geq 5 \mathrm{~cm} \text { below LCM, interme- } \\
\text { diate- } 2-\text { or high-risk, or interme- } \\
\text { diate- } 1 \text {-risk with symptomatic } \\
\text { organomegaly, }<10 \% \text { peripheral } \\
\text { blasts, ANC }>0.75 \times 10^{9} / \mathrm{L} \text {, current or } \\
\text { prior rux required }\end{array}$ & $\begin{array}{l}\text { Comparator: BAT; grade } \geq 2 \text { PN not } \\
\text { allowed; designed for rux failures } \\
\text { and rux-intolerant patients }\end{array}$ \\
\hline NCT02124746 & Momelotinib & II & $\begin{array}{l}\text { Long-term extension study for pa- } \\
\text { tients with PMF, post-PV/ET MF, PV } \\
\text { or ET who have tolerated momelo- } \\
\text { tinib and achieved stable disease or } \\
\text { better on a previous trial }\end{array}$ & $\begin{array}{l}\text { Patients receive momelotinib for } \\
\text { up to } 4 \mathrm{y}\end{array}$ \\
\hline $\begin{array}{l}\text { NCT01969838 } \\
\text { (SIMPLIFY-1) }\end{array}$ & Momelotinib vs rux & III & $\begin{array}{l}\text { PMF or post-PV/ET MF requir- } \\
\text { ing therapy, intermediate-2- or } \\
\text { high-risk, or intermediate-1-risk } \\
\text { with symptomatic organomegaly, } \\
\text { anemia (Hgb }<10 \mathrm{~g} / \mathrm{dL} \text { ), and/or } \\
\text { unresponsive to available therapy; } \\
\text { platelets } \geq 50 \times 10^{9} / \mathrm{L} \text {, ANC } \geq 0.75 \mathrm{x} \\
10 \% / \mathrm{L},<10 \% \text { peripheral blasts }\end{array}$ & $\begin{array}{l}\text { Frontline, head-to-head study; pa- } \\
\text { tients must be JAK inhibitor-naïve; } \\
\text { grade } \geq 2 \text { PN not allowed }\end{array}$ \\
\hline $\begin{array}{l}\text { NCT02055781 } \\
\text { (PERSIST-2) }\end{array}$ & $\begin{array}{l}\text { Pacritinib }(400 \mathrm{mg} \\
\text { daily or } 200 \mathrm{mg} \text { bid) }\end{array}$ & III & $\begin{array}{l}\text { Intermediate- or high-risk MF with } \\
\text { platelets } \leq 100 \times 10^{9} / \mathrm{L} \text {, spleen pal- } \\
\text { pable } \geq 5 \mathrm{~cm} \text { below LCM, MPN-SAF } \\
\text { TSS } \geq 13\end{array}$ & $\begin{array}{l}\text { Comparator: BAT; cannot have had } \\
>2 \text { prior JAK2 inhibitors }\end{array}$ \\
\hline $\begin{array}{l}\text { NCT01773187 } \\
\text { (PERSIST-1) }^{94}\end{array}$ & $\begin{array}{l}\text { Pacritinib (400 mg } \\
\text { daily) }\end{array}$ & III & $\begin{array}{l}\text { Intermediate- or high-risk MF, } \\
\text { spleen palpable } \geq 5 \mathrm{~cm} \text { below LCM, } \\
\text { MPN-SAF TSS } \geq 13\end{array}$ & $\begin{array}{l}\text { Comparator: BAT; prior JAK2 } \\
\text { inhibitor not allowed }\end{array}$ \\
\hline NCT02564536 & $\begin{array}{l}\text { Pacritinib ( } 200 \mathrm{mg} \\
\text { bid) plus decitabine }\end{array}$ & 0 (pilot) & $\begin{array}{l}\text { Intermediate- or high-risk PMF or } \\
\text { post-PV/ET MF who are unrespon- } \\
\text { sive to or unable to receive current } \\
\text { therapy, or patients with MDS/ } \\
\text { MPN; ANC } \geq 0.5 \times 10^{9} / L,<20 \% \text { BM } \\
\text { blasts }\end{array}$ & $\begin{array}{l}\text { Decitabine administered } \\
\text { subcutaneously on days } 1,5,8,12, \\
15,19,22, \text { and } 26 \text { of a } 28-d \text { cycle }\end{array}$ \\
\hline NCT01423851 & NS-018 & $\mathrm{I} / \mathrm{II}$ & $\begin{array}{l}\text { PMF or post-PV/ET MF requir- } \\
\text { ing therapy; prior JAK2 inhibitor } \\
\text { therapy required, R/R or intolerant; } \\
\text { ANC }>1 \times 10^{9} / \mathrm{L} \text {, platelets }>25 \times 10^{9} / \mathrm{L}\end{array}$ & Preliminary results available $\mathrm{e}^{95}$ \\
\hline
\end{tabular}

Abbreviations: ANC, absolute neutrophil count; BAT, best available therapy; BM, bone marrow; ET, essential thrombocythemia; Hgb, hemoglobin; JAK, Janus kinase; LCM, left costal margin; MDS, myelodysplastic syndrome; MF, myelofibrosis; MPN, myeloproliferative neoplasm; MPN-SAF TSS, MPN Symptom Assessment Form Total Symptom Score; PMF, primary myelofibrosis; PN, peripheral neuropathy; PV, polycythemia vera; R/R, relapsed/ refractory; rux, ruxolitinib; TD, transfusion-dependent. 
Bose and Verstovsek

responses in $53 \%$ and $16.7 \%$, respectively. ${ }^{87,88}$ In both studies, spleen response was a composite of $50 \%$ or greater reduction in palpable spleen length for those with baseline splenomegaly $10 \mathrm{~cm}$ or greater, and resolution of palpable splenomegaly for those with baseline splenomegaly between 5 and $10 \mathrm{~cm}$, and had to last at least 8 weeks. Similarly, anemia response was a composite of the achievement of transfusion independence for 12 weeks or greater in those who were transfusion-dependent at baseline, and a sustained increase in hemoglobin level of $2 \mathrm{~g} / \mathrm{dL}$ or greater in those who were not transfusion-dependent at baseline, but had a baseline hemoglobin level of less than $10 \mathrm{~g} / \mathrm{dL}$. In the second study, the spleen response rate at 24 weeks by imaging was $45.8 \% .{ }^{88}$ Most patients had a $50 \%$ or greater improvement in pruritus, cough, bone pain, fever, and night sweats at 3 months in the first study, ${ }^{87}$ and the MPN-SAF TSS $^{23}$ decreased by $50 \%$ or greater at 6 months in approximately one-third of patients in the second study. ${ }^{88}$ Peripheral neuropathy (PN) is an important side effect of momelotinib. ${ }^{89}$ In the Mayo Clinic experience, momelotinib treatment-emergent $\mathrm{PN}$ occurred in 44 of 100 patients (44\%) with MF; median time to onset was 32 weeks and duration was 11 months. ${ }^{89}$ Improvement after dose reduction or discontinuation of momelotinib was documented in only 2 patients. Treatment-emergent PN did not correlate with initial or maximal momelotinib dose, or with prior thalidomide exposure. ${ }^{89}$ In the second study that used twice daily dosing of momelotinib, PN also occurred in 44\% of subjects (27 of 61 ) and was mainly sensory in nature ${ }^{88}$; all but 2 were grade $1 / 2$ events. Median time to onset was again 227 days (32 weeks), and overall, 5 subjects discontinued from the study because of PN. ${ }^{88}$ Multiple doses of momelotinib (150, 200, and $250 \mathrm{mg}$ twice daily, 300 mg once daily) have been tested in these studies, ${ }^{87,88}$ and the 300-mg daily dose is the one currently being evaluated in phase III studies (Table 3).

The JAK2/FMS-like receptor tyrosine kinase 3 (FLT3) inhibitor pacritinib also potently inhibits colony-stimulating factor 1 receptor, and interleukin-1 receptor-associated kinase 1 and does not inhibit JAK1; these actions may explain its lack of myelosuppression..$^{90}$ Pacritinib was evaluated in a phase II study in 35 patients with MF who were either newly diagnosed with an intermediate- or high-risk Lille score ${ }^{91}$ and not candidates for stan- dard therapy or had splenomegaly that was poorly controlled with standard therapy. ${ }^{92}$ Patients with any degree of cytopenia were eligible. A total of $42 \%$ of evaluable patients experienced a $50 \%$ or greater reduction in spleen size from baseline up to week 24 by physical examination (31\% of evaluable patients had $\geq 35 \%$ SVR on imaging) and $48.4 \%$ of patients had a $50 \%$ or greater reduction in TSS (using the Myelofibrosis Symptom Assessment Form [MFSAF] $)^{93}$ from baseline up to week 24. Grade 1 or 2 diarrhea $(69 \%)$ and nausea $(49 \%)$ were the most common adverse events. ${ }^{92}$ Pacritinib was then compared with BAT (excluding ruxolitinib) in the phase III PERSIST-1 trial in patients with MF. ${ }^{94}$ SVR rates at week 24 were $19.1 \%$ for pacritinib versus $4.7 \%$ for BAT in the intention-to-treat (ITT) analysis, and $25 \%$ versus $5.9 \%$, respectively, among evaluable patients. A total of $24.5 \%$ versus $6.5 \%$ (ITT) and $40.9 \%$ versus $9.9 \%$ (evaluable population) of patients, respectively, had a $50 \%$ or greater reduction in their MPN-SAF TSS. ${ }^{23} \mathrm{~A}$ total of $25.7 \%$ of pacritinib patients became transfusion-independent versus $0 \%$ of patients randomized to BAT. Most adverse events in the pacritinib arm were grade $1 / 2$ diarrhea, nausea, or vomiting. ${ }^{94}$ However, the FDA placed a "full clinical hold" on pacritinib after reports of deaths due to intracranial hemorrhage, cardiac failure, and cardiac arrest in the phase III PERSIST-2 trial (Table 3).

NS-018 is a JAK2-selective inhibitor currently undergoing phase II testing in patients with intermediate- or high-risk MF (ClinicalTrials.gov identifier: NCT01423851; Table 3). The recommended phase II dose based on data from the phase I portion of this trial is $300 \mathrm{mg} / \mathrm{d} .{ }^{95}$ A total of 23 of the 48 patients enrolled on the phase I portion had received prior JAK2 inhibitor therapy. A $50 \%$ or greater reduction in palpable spleen size was achieved in $56 \%$ of patients, including $47 \%$ of patients with prior JAK inhibitor treatment. ${ }^{95}$ After 3 cycles of treatment, reductions in MFSAF scores ${ }^{93}$ were observed for all symptoms, and 11 of 30 (37\%) evaluable patients had a reduction in BM fibrosis by 1 grade or more, although the JAK2 V617F allelic burden was largely unchanged. ${ }^{95}$ There was a hint from this study that NS-018 may elicit an early improvement in BM fibrosis in some patients, and that this might correlate with improvements in anemia and thrombocytopenia, as well as with spleen responses; however, the numbers were small, precluding firm conclusions. The cytokine 
Drug Development in Myeloproliferative Neoplasms

regulation profile for NS-018 appears to be slightly different from that of ruxolitinib. ${ }^{95}$

\section{Antifibrotic Agents}

PRM-151 is an intravenously administered recombinant form of human pentraxin-2 (serum amyloid $\mathrm{P}$, a highly conserved, naturally circulating plasma protein and soluble pattern recognition receptor of the innate immune system that may localize specifically to sites of injury and function to aid in the removal of damaged tissue $)^{96}$ that was studied on weekly and every-4-week schedules, either alone or in conjunction with ruxolitinib, in 27 patients with intermediate- or high-risk ${ }^{97} \mathrm{MF}$ and grade 2 or greater BM fibrosis. ${ }^{98}$ More than half had received a prior JAK inhibitor. In the first stage of the trial ( 24 weeks of therapy), 9 of $26(35 \%)$ evaluable patients experienced response, 4 had symptoms of clinical improvement, and $6 \mathrm{had}$ BM fibrosis responses. ${ }^{22}$ PRM-151 was well-tolerated in all 4 arms. ${ }^{98}$ A total of 18 patients continued onto an extension phase (stage 2), and data on 13 who had completed at least 72 weeks of treatment were presented last year. ${ }^{99}$ Symptom and spleen responses continued to improve over time, as did anemia and thrombocytopenia, with most transfusion-dependent patients becoming transfusion-independent. A total of $54 \%$ had a BM morphologic response, and $85 \%$ showed a response via computer-assisted image analysis; $69 \%$ and $38 \%$ of patients experienced a $50 \%$ or greater and $100 \%$ reductions from baseline, respectively, in their TSS ${ }^{23}$ between 24 and 72 weeks. ${ }^{99}$ In 5 patients with baseline hemoglobin level less than 10 $\mathrm{g} / \mathrm{dL}$, the median hemoglobin level increased from $8.6 \mathrm{~g} / \mathrm{dL}$ at baseline to $10.7 \mathrm{~g} / \mathrm{dL}$ at week 72 . Three of these patients who were receiving transfusions at baseline achieved transfusion independence, with durations of 32 to 60 weeks. ${ }^{99}$ Similarly, of 9 patients with baseline platelet counts of less than $100 \times 10^{9} / \mathrm{L}$, the median platelet count increased from $38 \times 10^{9} / \mathrm{L}$ at baseline to $52 \times 10^{9} / \mathrm{L}$. Four of these patients were receiving platelet transfusions at baseline, and all became transfusion-independent. ${ }^{99}$ No serious adverse events related to PRM-151 occurred. ${ }^{99}$

\section{Imetelstat}

Imetelstat is an intravenously administered lipidconjugated oligonucleotide telomerase inhibitor that was studied in 33 patients with intermediate-2or high-risk ${ }^{100} \mathrm{MF}, 48 \%$ of whom had received prior
JAK inhibitor therapy ${ }^{101} ; 7$ patients $(21 \%)$ achieved a complete or partial response. ${ }^{22} \mathrm{BM}$ fibrosis was reversed in all 4 patients with a complete response, 3 of whom also experienced a molecular response. Responses did not correlate with baseline telomere length. Responses were restricted to patients with mutated JAK2, and were not seen in the presence of ASXL1 mutations. ${ }^{101}$ Furthermore, responses appeared to correlate with the presence of mutations in the RNA splicing genes, SF3B1 or U2AF1. Grade $3 / 4$ myelosuppression and grade $1 / 2$ hepatotoxicity were frequent. However, none of the abnormalities in liver-enzyme levels were linked to clinically overt liver damage and most were reversible. ${ }^{101}$ Imetelstat, 9.4 or $4.7 \mathrm{mg} / \mathrm{kg}$ every 3 weeks, is currently being evaluated in patients with intermediate-2- and high-risk MF that failed to respond to therapy with a JAK inhibitor in a phase II study (ClinicalTrials.gov identifier: NCT02426086). In a recent press release, Geron Corporation (Menlo Park, CA) announced that the $4.7-\mathrm{mg} / \mathrm{kg}$ dose will not be evaluated further due to insufficient activity. ${ }^{102}$

\section{Conclusions}

This review summarizes the drugs currently in clinical development for MPNs, with a focus on those most likely to influence MPN management guidelines over the next several years, as has occurred with ruxolitinib. It is possible that ruxolitinib will be used in lower-risk patients with MF, particularly those with adverse genomic features, based on findings from the ReTHINK study. Ruxolitinib-based combinations, particularly with DNMTI and HDACIs, as well as with antianemia medications, are likely to gain widespread acceptance. Regulatory approval of one or more JAK inhibitors beyond ruxolitinib is anticipated, although the discontinuation of many of these agents tells a cautionary tale. The experience with PRM-151 and imetelstat is limited, but these drugs are attractive by virtue of their ability to improve or reverse BM fibrosis.

Despite the success of ruxolitinib, there remain many unmet needs in terms of drug development for patients with MF. First and foremost, the survival of these patients remains short, and the modest gains in survival achieved with ruxolitinib may be more attributable to improvement in appetite, weight gain, correction of hypocholesterolemia, and reversal of 
cachexia than to actual targeting of the neoplastic clone. ${ }^{103}$ Other areas where novel therapeutics are needed include anemia of MF, whether from the disease or worsened by ruxolitinib. The infectious risks of long-term JAK inhibitor therapy remain an important concern. Ruxolitinib's approval is a welcome advancement in the treatment of PV, as is the advent of ropeginterferon- $\alpha$. Approval of these or other agents is awaited by patients with ET who have troublesome symptoms. Finally, no current therapy reliably prevents progression of $\mathrm{PV}$ or ET to MF or acute myeloid leukemia.

\section{References}

1. Vannucchi AM, Barbui T, Cervantes F, et al. Philadelphia chromosomenegative chronic myeloproliferative neoplasms: ESMO Clinical Practice Guidelines for diagnosis, treatment and follow-up. Ann Oncol 2015;26(Suppl 5):v85-99.

2. Cervantes F, Dupriez B, Passamonti F, et al. Improving survival trends in primary myelofibrosis: an international study. J Clin Oncol 2012;30:29812987.

3. Tefferi A, Guglielmelli P, Larson DR, et al. Long-term survival and blast transformation in molecularly annotated essential thrombocythemia, polycythemia vera, and myelofibrosis. Blood 2014;124:2507-2513; quiz 2615.

4. Tefferi A, Rumi E, Finazzi G, et al. Survival and prognosis among 1545 patients with contemporary polycythemia vera: an international study. Leukemia 2013;27:1874-1881.

5. Anand S, Stedham F, Gudgin E, et al. Increased basal intracellular signaling patterns do not correlate with JAK2 genotype in human myeloproliferative neoplasms. Blood 2011;118:1610-1621.

6. Rampal R, Al-Shahrour F, Abdel-Wahab O, et al. Integrated genomic analysis illustrates the central role of JAK-STAT pathway activation in myeloproliferative neoplasm pathogenesis. Blood 2014;123:e123-133.

7. Baxter EJ, Scott LM, Campbell PJ, et al. Acquired mutation of the tyrosine kinase JAK2 in human myeloproliferative disorders. Lancet 2005;365:1054-1061.

8. James C, Ugo V, Le Couedic JP, et al. A unique clonal JAK2 mutation leading to constitutive signalling causes polycythaemia vera. Nature 2005;434:1144-1148.

9. Kralovics R, Passamonti F, Buser AS, et al. A gain-of-function mutation of JAK2 in myeloproliferative disorders. N Engl J Med 2005;352:1779-1790.

10. Levine RL, Wadleigh M, Cools J, et al. Activating mutation in the tyrosine kinase JAK2 in polycythemia vera, essential thrombocythemia, and myeloid metaplasia with myelofibrosis. Cancer Cell 2005;7:387-397.

11. Scott LM, Tong W, Levine RL, et al. JAK2 exon 12 mutations in polycythemia vera and idiopathic erythrocytosis. $N$ Engl J Med 2007;356:459-468.

12. Pardanani AD, Levine RL, Lasho $T$, et al. MPL515 mutations in myeloproliferative and other myeloid disorders: a study of 1182 patients. Blood 2006;108:3472-3476.

13. Pikman $Y$, Lee BH, Mercher $T$, et al. MPLW515L is a novel somatic activating mutation in myelofibrosis with myeloid metaplasia. PLoS Med 2006;3:e270.

14. Klampfl T, Gisslinger H, Harutyunyan AS, et al. Somatic mutations of calreticulin in myeloproliferative neoplasms. N Engl J Med 2013;369:2379_ 2390.

15. Nangalia J, Massie CE, Baxter EJ, et al. Somatic CALR mutations in myeloproliferative neoplasms with nonmutated JAK2. N Engl J Med 2013;369:2391-2405.

16. Verstovsek S, Mesa RA, Gotlib J, et al. A double-blind, placebo-controlled trial of ruxolitinib for myelofibrosis. N Engl J Med 2012;366:799-807.

17. Harrison C, Kiladjian JJ, Al-Ali HK, et al. JAK inhibition with ruxolitinib versus best available therapy for myelofibrosis. N Engl J Med 2012;366:787798.
18. Vannucchi AM, Kiladjian JJ, Griesshammer M, et al. Ruxolitinib versus standard therapy for the treatment of polycythemia vera. N Engl J Med 2015;372:426-435.

19. Verstovsek S, Mesa RA, Gotlib JR, et al. Long-term outcomes of ruxolitinib (RUX) therapy in patients (pts) with myelofibrosis (MF): 5-year final efficacy and safety analysis from COMFORT-I [abstract]. J Clin Oncol 2016;35(Supp):Abstract 7012.

20. Harrison CN, Vannucchi AM, Kiladjian JJ, et al. Long-term findings from COMFORT-II, a phase 3 study of ruxolitinib vs best available therapy for myelofibrosis. Leukemia 2016;30:1701-1707.

21. Mesa RA, Gotlib J, Gupta V, et al. Effect of ruxolitinib therapy on myelofibrosis-related symptoms and other patient-reported outcomes in COMFORT-I: a randomized, double-blind, placebo-controlled trial. J Clin Oncol 2013;31:1285-1292.

22. Tefferi A, Cervantes F, Mesa R, et al. Revised response criteria for myelofibrosis: International Working Group-Myeloproliferative Neoplasms Research and Treatment (IWG-MRT) and European LeukemiaNet (ELN) consensus report. Blood 2013;122:1395-1398.

23. Emanuel RM, Dueck AC, Geyer HL, et al. Myeloproliferative neoplasm (MPN) symptom assessment form total symptom score: prospective international assessment of an abbreviated symptom burden scoring system among patients with MPNs. J Clin Oncol 2012;30:4098-4103.

24. Guglielmelli P, Rotunno G, Bogani C, et al. Ruxolitinib is an effective treatment for CALR-positive patients with myelofibrosis. Br J Haematol 2016;173:938-940.

25. Stein BL, Swords R, Hochhaus A, Giles F. Novel myelofibrosis treatment strategies: potential partners for combination therapies. Leukemia 2014;28:2139-2147.

26. Kroger NM, Deeg JH, Olavarria E, et al. Indication and management of allogeneic stem cell transplantation in primary myelofibrosis: a consensus process by an EBMT/ELN international working group. Leukemia 2015;29:2126-2133.

27. Spoerl S, Mathew NR, Bscheider M, et al. Activity of therapeutic JAK $1 / 2$ blockade in graft-versus-host disease. Blood 2014;123:3832-3842.

28. Zeiser R, Burchert A, Lengerke $C$, et al. Ruxolitinib in corticosteroidrefractory graft-versus-host disease after allogeneic stem cell transplantation: a multicenter survey. Leukemia 2015;29:2062-2068.

29. Landolfi R, Marchioli R, Kutti J, et al. Efficacy and safety of low-dose aspirin in polycythemia vera. N Engl J Med 2004;350:114-124.

30. Cortelazzo S, Finazzi G, Ruggeri M, et al. Hydroxyurea for patients with essential thrombocythemia and a high risk of thrombosis. N Engl J Med 1995;332:1132-1136.

31. Harrison CN, Campbell PJ, Buck G, et al. Hydroxyurea compared with anagrelide in high-risk essential thrombocythemia. N Engl J Med 2005;353:33-45.

32. Gisslinger H, Gotic M, Holowiecki J, et al. Anagrelide compared with hydroxyurea in WHO-classified essential thrombocythemia: the ANAHYDRET Study, a randomized controlled trial. Blood 2013;121:1720-1728.

33. Marchioli R, Finazzi G, Specchia G, et al. Cardiovascular events and intensity of treatment in polycythemia vera. N Engl J Med 2013;368:2233.

34. Geyer HL, Scherber RM, Dueck AC, et al. Distinct clustering of symptomatic burden among myeloproliferative neoplasm patients: retrospective assessment in 1470 patients. Blood 2014;123:3803-3810.

35. Mesa RA, Niblack J, Wadleigh $M$, et al. The burden of fatigue and quality of life in myeloproliferative disorders (MPDs): an international Internet based survey of 1179 MPD patients. Cancer 2007;109:68-76.

36. Scherber R, Dueck AC, Johansson P, et al. The Myeloproliferative Neoplasm Symptom Assessment Form (MPN-SAF): international prospective validation and reliability trial in 402 patients. Blood 2011;118:401-408.

37. Verstovsek S, Vannucchi AM, Griesshammer M, et al. Ruxolitinib versus best available therapy in patients with polycythemia vera: 80 -week followup from the RESPONSE trial. Haematologica 2016;101:821-829.

38. Kiladjian JJ, Cassinat B, Chevret S, et al. Pegylated interferon-alfa-2a induces complete hematologic and molecular responses with low toxicity in polycythemia vera. Blood 2008;112:3065-3072.

39. Quintas-Cardama A, Kantarjian H, Manshouri T, et al. Pegylated interferon alfa-2a yields high rates of hematologic and molecular response in patients with advanced essential thrombocythemia and polycythemia vera. J Clin Oncol 2009;27:5418-5424.

40. Masarova L, Verstovsek S, Patel KP, et al. Efficacy and safety of pegylated interferon alpha-2a in patients with essential thrombocythemia and 
Drug Development in Myeloproliferative Neoplasms

polycythemia vera: results after a median 7 -year follow-up of a phase 2 study [abstract]. Blood 2015;126:Abstract 60.

41. Verger $\mathrm{E}$, Cassinat $\mathrm{B}$, Chauveau $\mathrm{A}$, et al. Clinical and molecular response to interferon-alpha therapy in essential thrombocythemia patients with CALR mutations. Blood 2015;126:2585-2591.

42. Gisslinger $\mathrm{H}$, Zagrijtschuk $\mathrm{O}$, Buxhofer-Ausch $\mathrm{V}$, et al. Ropeginterferon alfa-2b, a novel IFNalpha-2b, induces high response rates with low toxicity in patients with polycythemia vera. Blood 2015;126:1762-1769.

43. Vannucchi AM, Verstovsek S, Guglielmelli P, et al. Ruxolitinib (RUX) reduces JAK2V617F allele burden (AB) in patients (pts) with polycythemia vera (PV) enrolled in the response study. Presented at the 21st Congress of the European Hematology Association; June 9-12, 2016; Copenhagen, Denmark.

44. Vainchenker W, Delhommeau F, Constantinescu SN, Bernard OA. New mutations and pathogenesis of myeloproliferative neoplasms. Blood 2011;118:1723-1735.

45. Kralovics R, Teo SS, Li S, et al. Acquisition of the V617F mutation of JAK2 is a late genetic event in a subset of patients with myeloproliferative disorders. Blood 2006;108:1377-1380.

46. Ortmann CA, Kent DG, Nangalia J, et al. Effect of mutation order on myeloproliferative neoplasms. N Engl J Med 2015;372:601-612.

47. Kiladjian JJ, Masse A, Cassinat B, et al. Clonal analysis of erythroid progenitors suggests that pegylated interferon alpha-2a treatment targets JAK2V617F clones without affecting TET2 mutant cells. Leukemia 2010;24:1519-1523.

48. Pieri L, Pancrazzi A, Pacilli A, et al. JAK2V617F complete molecular remission in polycythemia vera/essential thrombocythemia patients treated with ruxolitinib. Blood 2015;125:3352-3353.

49. Baerlocher GM, Oppliger Leibundgut E, Ottmann OG, et al. Telomerase inhibitor imetelstat in patients with essential thrombocythemia. N Engl J Med 2015;373:920-928.

50. Guerini V, Barbui V, Spinelli O, et al. The histone deacetylase inhibitor ITF2357 selectively targets cells bearing mutated JAK2(V617F). Leukemia 2008;22:740-747.

51. Akada H, Akada S, Gajra A, et al. Efficacy of vorinostat in a murine model of polycythemia vera. Blood 2012;119:3779-3789.

52. Andersen CL, McMullin MF, Ejerblad E, et al. A phase II study of vorinostat (MK-0683) in patients with polycythaemia vera and essential thrombocythaemia. Br J Haematol 2013;162:498-508.

53. Rambaldi A, Dellacasa CM, Finazzi G, et al. A pilot study of the histonedeacetylase inhibitor givinostat in patients with JAK2V617F positive chronic myeloproliferative neoplasms. Br J Haematol 2010;150:446-455.

54. Finazzi G, Vannucchi AM, Martinelli V, et al. A phase II study of Givinostat in combination with hydroxycarbamide in patients with polycythaemia vera unresponsive to hydroxycarbamide monotherapy. Br J Haematol 2013;161:688-694.

55. Cervantes F. How I treat myelofibrosis. Blood 2014;124:2635-2642.

56. Harrison CN, Vannucchi AM, Kiladjian J, et al. Long-term efficacy and safety in COMFORT-II, a phase 3 study comparing ruxolitinib with best available therapy for the treatment of myelofibrosis: 5-year final study results. Blood 2015;126:59.

57. Vannucchi AM, Lasho TL, Guglielmelli P, et al. Mutations and prognosis in primary myelofibrosis. Leukemia 2013;27:1861-1869.

58. Parganas E, Wang D, Stravopodis D, et al. Jak2 is essential for signaling through a variety of cytokine receptors. Cell 1998;93:385-395.

59. Meyer SC, Levine RL. Molecular pathways: molecular basis for sensitivity and resistance to JAK kinase inhibitors. Clin Cancer Res 2014;20:20512059.

60. Daver N, Cortes J, Newberry K, et al. Ruxolitinib in combination with lenalidomide as therapy for patients with myelofibrosis. Haematologica 2015;100:1058-1063.

61. Gowin KM, Kosiorek HE, Dueck AC, et al. Final analysis of a multicenter pilot phase 2 study of ruxolitinib and danazol in patients with myelofibrosis [abstract]. Blood 2015;126:Abstract 1618.

62. Dussiot M, Maciel TT, Fricot A, et al. An activin receptor IIA ligand trap corrects ineffective erythropoiesis in beta-thalassemia. Nat Med 2014:20:398-407.

63. Giagounidis A, Platzbecker U, Germing U, et al. Luspatercept treatment leads to long term increases in hemoglobin and reductions in transfusion burden in patients with low or intermediate-1 risk myelodysplastic syndromes (MDS): preliminary results from the phase 2 PACE-MDS Extension Study [abstract]. Blood 2015;126:Abstract 92.
64. Mascarenhas J, Roper N, Chaurasia P, Hoffman R. Epigenetic abnormalities in myeloproliferative neoplasms: a target for novel therapeutic strategies. Clin Epigenetics 2011;2:197-212.

65. Bali P, Pranpat M, Bradner J, et al. Inhibition of histone deacetylase 6 acetylates and disrupts the chaperone function of heat shock protein 90: a novel basis for antileukemia activity of histone deacetylase inhibitors. J Biol Chem 2005;280:26729-26734.

66. Wang Y, Fiskus W, Chong DG, et al. Cotreatment with panobinostat and JAK2 inhibitor TG101209 attenuates JAK2V617F levels and signaling and exerts synergistic cytotoxic effects against human myeloproliferative neoplastic cells. Blood 2009;114:5024-5033.

67. Mascarenhas J, Lu M, Li T, et al. A phase I study of panobinostat (LBH589) in patients with primary myelofibrosis (PMF) and post-polycythaemia vera/essential thrombocythaemia myelofibrosis (post-PV/ET MF). Br J Haematol 2013;161:68-75.

68. DeAngelo DJ, Mesa RA, Fiskus W, et al. Phase II trial of panobinostat, an oral pan-deacetylase inhibitor in patients with primary myelofibrosis, postessential thrombocythaemia, and post-polycythaemia vera myelofibrosis. Br J Haematol 2013;162:326-335.

69. Quintas-Cardama A, Kantarjian H, Estrov Z, et al. Therapy with the histone deacetylase inhibitor pracinostat for patients with myelofibrosis. Leuk Res 2012;36:1124-1127.

70. Harrison $\mathrm{CN}$, Kiladjian JJ, Heidel FH, et al. Efficacy, safety, and confirmation of the recommended phase 2 starting dose of the combination of ruxolitinib (RUX) and panobinostat (PAN) in patients (pts) with myelofibrosis (MF) [abstract]. Blood 2015;126:Abstract 4060.

71. Cervantes F, Dupriez B, Pereira A, et al. New prognostic scoring system for primary myelofibrosis based on a study of the International Working Group for Myelofibrosis Research and Treatment. Blood 2009;113:2895-2901.

72. Nischal S, Bhattacharyya S, Christopeit M, et al. Methylome profiling reveals distinct alterations in phenotypic and mutational subgroups of myeloproliferative neoplasms. Cancer Res 2013;73:1076-1085.

73. Quintas-Cardama A, Tong W, Kantarjian H, et al. A phase II study of 5-azacitidine for patients with primary and post-essential thrombocythemia/ polycythemia vera myelofibrosis. Leukemia 2008;22:965-970.

74. Daver NG, Cortes JE, Zhou L, et al. Ruxolitinib (RUX) in combination with 5-azacytidine (AZA) as therapy for patients (pts) with myelofibrosis (MF) [abstract]. Haematologica 2015;15(Suppl 2):Abstract 808.

75. Thepot S, Itzykson R, Seegers V, et al. Treatment of progression of Philadelphia-negative myeloproliferative neoplasms to myelodysplastic syndrome or acute myeloid leukemia by azacitidine: a report on 54 cases on the behalf of the Groupe Francophone des Myelodysplasies (GFM). Blood 2010;116:3735-3742.

76. Badar T, Kantarjian HM, Ravandi F, et al. Therapeutic benefit of decitabine, a hypomethylating agent, in patients with high-risk primary myelofibrosis and myeloproliferative neoplasm in accelerated or blastic/ acute myeloid leukemia phase. Leuk Res 2015;39:950-956.

77. Kamishimoto J, Tago K, Kasahara T, Funakoshi-Tago M. Akt activation through the phosphorylation of erythropoietin receptor at tyrosine 479 is required for myeloproliferative disorder-associated JAK2 V617F mutantinduced cellular transformation. Cell Signal 2011;23:849-856.

78. Fiskus $W$, Verstovsek $S$, Manshouri $T$, et al. Dual PI3K/AKT/mTOR inhibitor BEZ235 synergistically enhances the activity of JAK2 inhibitor against cultured and primary human myeloproliferative neoplasm cells. Mol Cancer Ther 2013;12:577-588.

79. Durrant S, Nagler A, Vannucchi AM, et al. An open-label, multicenter, 2 -arm, dose-finding, phase $1 \mathrm{~b}$ study of the combination of ruxolitinib and buparlisib (BKM120) in patients with myelofibrosis: results from HARMONY study [abstract]. Blood 2015;126:Abstract 827.

80. Guglielmelli P, Barosi G, Rambaldi A, et al. Safety and efficacy of everolimus, a mTOR inhibitor, as single agent in a phase $1 / 2$ study in patients with myelofibrosis. Blood 2011;118:2069-2076.

81. Klein C, Zwick A, Kissel S, et al. Ptch2 loss drives myeloproliferation and myeloproliferative neoplasm progression. J Exp Med 2016;213:273-290.

82. Bhagwat $\mathrm{N}$, Keller MD, Rampal R, et al. Improved efficacy of combination of JAK2 and hedgehog inhibitors in myelofibrosis [abstract]. Blood 2013;122:Abstract 666.

83. Gupta V, Harrison CN, Hasselbalch HC, et al. Phase $1 b / 2$ study of the efficacy and safety of sonidegib (LDE225) in combination with ruxolitinib (INC424) in patients with myelofibrosis [abstract]. Blood 2015;126:Abstract 825.

84. Geyer HL, Mesa RA. Therapy for myeloproliferative neoplasms: when, which agent, and how? Blood 2014;124:3529-3537. 
85. Pardanani A, Laborde RR, Lasho TL, et al. Safety and efficacy of CYT387, a JAK1 and JAK2 inhibitor, in myelofibrosis. Leukemia 2013;27:13221327.

86. Asshoff M, Warr M, Haschka D, et al. The Jak1/Jak2 inhibitor momelotinib inhibits Alk2, decreases hepcidin production and ameliorates anemia of chronic disease (ACD) in rodents [abstract]. Blood 2015;126:A bstract 538.

87. Pardanani A, Gotlib JR, Gupta V, et al. Update on the long-term efficacy and safety of momelotinib, a JAK1 and JAK2 inhibitor, for the treatment of myelofibrosis [abstract]. Blood 2013;122:Abstract 108.

88. Gupta V, Mesa RA, Deininger MW, et al. A phase $1 / 2$, open-label study evaluating twice-daily administration of momelotinib in myelofibrosis [published online ahead of print September 15, 2016]. Haematologica, pii: haematol.2016.148924.

89. Abdelrahman RA, Begna KH, Al-Kali A, et al. Momelotinib treatmentemergent neuropathy: prevalence, risk factors and outcome in 100 patients with myelofibrosis. Br J Haematol 2015;169:77-80.

90. Singer JW, Al-Fayoumi S, Ma H, et al. Comprehensive kinase profile of pacritinib, a nonmyelosuppressive Janus kinase 2 inhibitor. J Exp Pharmacol 2016;8:11-19.

91. Dupriez B, Morel P, Demory JL, et al. Prognostic factors in agnogenic myeloid metaplasia: a report on 195 cases with a new scoring system. Blood 1996;88:1013-1018.

92. Komrokji RS, Seymour JF, Roberts AW, et al. Results of a phase 2 study of pacritinib (SB1518), a JAK2/JAK2(V617F) inhibitor, in patients with myelofibrosis. Blood 2015;125:2649-2655.

93. Mesa RA, Schwager S, Radia D, et al. The Myelofibrosis Symptom Assessment Form (MFSAF): an evidence-based brief inventory to measure quality of life and symptomatic response to treatment in myelofibrosis. Leuk Res 2009;33:1199-1203.

94. Mesa RA, Egyed M, Szoke A, et al. Pacritinib (PAC) vs best available therapy (BAT) in myelofibrosis (MF): 60 week follow-up of the phase III PERSIST-1 trial [abstract]. J Clin Oncol 2016;34:Abstract 7065.

95. Verstovsek S, Talpaz M, Ritchie E, et al. A Phase I, open-label, doseescalation, multicenter study of the JAK2 inhibitor NS-018 in patients with myelofibrosis [published online ahead of print September 2, 2016]. Leukemia, doi: 10.1038/leu.2016.215.

96. Duffield JS, Lupher ML Jr. PRM-151 (recombinant human serum amyloid P/pentraxin 2) for the treatment of fibrosis. Drug News Perspect 2010;23:305-315.

97. Passamonti F, Cervantes F, Vannucchi AM, et al. A dynamic prognostic model to predict survival in primary myelofibrosis: a study by the IWG-
MRT (International Working Group for Myeloproliferative Neoplasms Research and Treatment). Blood 2010;115:1703-1708.

98. Verstovsek S, Mesa RA, Foltz LM, et al. Phase 2 trial of PRM-151, an anti-fibrotic agent, in patients with myelofibrosis: stage 1 results [abstract] Blood 2014;124:Abstract 713.

99. Verstovsek S, Mesa RA, Foltz LM, et al. PRM-151 in myelofibrosis: durable efficacy and safety at 72 weeks [abstract]. Blood 2015;126:Abstract 56.

100. Gangat N, Caramazza D, Vaidya R, et al. DIPSS plus: a refined Dynamic International Prognostic Scoring System for primary myelofibrosis that incorporates prognostic information from karyotype, platelet count, and transfusion status. J Clin Oncol 2011;29:392-397.

101. Tefferi A, Lasho TL, Begna $\mathrm{KH}$, et al. A pilot study of the telomerase inhibitor imetelstat for myelofibrosis. N Engl J Med 2015;373:908-919.

102. Geron Provides Update on Imetelstat Trials Being Conducted by Janssen. Geron Web site. Available at: http://ir.geron.com/phoenix. zhtml?c=67323\&p=irol-newsArticle\&ID=2201055. Accessed September $18,2016$.

103. Mascarenhas J, Hoffman R. A comprehensive review and analysis of the effect of ruxolitinib therapy on the survival of patients with myelofibrosis. Blood 2013;121:4832-4837.

104. Barosi G, Birgegard G, Finazzi G, et al. A unified definition of clinical resistance and intolerance to hydroxycarbamide in polycythaemia vera and primary myelofibrosis: results of a European LeukemiaNet (ELN) consensus process. Br J Haematol 2010;148:961-963.

105. Barosi G, Birgegard G, Finazzi G, et al. Response criteria for essential thrombocythemia and polycythemia vera: result of a European LeukemiaNet consensus conference. Blood 2009;113:4829-4833.

106. Tefferi A, Verstovsek S, Barosi G, et al. Pomalidomide is active in the treatment of anemia associated with myelofibrosis. J Clin Oncol 2009;27:4563-4569.

107. Tefferi A, Passamonti F, Barbui T, et al. Phase 3 study of pomalidomide in myeloproliferative neoplasm (MPN)-associated myelofibrosis with RBCtransfusion-dependence [abstract]. Blood 2013;122:Abstract 394.

108. Radin AI, Kim HT, Grant BW, et al. Phase II study of alpha2 interferon in the treatment of the chronic myeloproliferative disorders (E5487): a trial of the Eastern Cooperative Oncology Group. Cancer 2003;98:100-109.

109. Jabbour E, Kantarjian H, Cortes J, et al. PEG-IFN-alpha-2b therapy in BCR-ABL-negative myeloproliferative disorders: final result of a phase 2 study. Cancer 2007;110:2012-2018.

110. Silver RT, Vandris K, Goldman JJ. Recombinant interferon-alpha may retard progression of early primary myelofibrosis: a preliminary report. Blood 2011;117:6669-6672. 